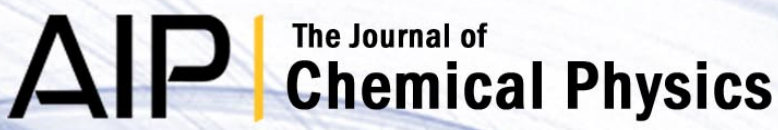

Fully relativistic calculations on the potential energy surfaces of the lowest 23 states of molecular chlorine

Luiz Guilherme de Macedo and Wibe A. de Jong

Citation: J. Chem. Phys. 128, 041101 (2008); doi: 10.1063/1.2827457

View online: http://dx.doi.org/10.1063/1.2827457

View Table of Contents: http://jcp.aip.org/resource/1/JCPSA6/v128/i4

Published by the AIP Publishing LLC.

Additional information on J. Chem. Phys.

Journal Homepage: http://jcp.aip.org/

Journal Information: http://jcp.aip.org/about/about_the_journal

Top downloads: http://jcp.aip.org/features/most_downloaded

Information for Authors: http://jcp.aip.org/authors

\section{ADVERTISEMENT}

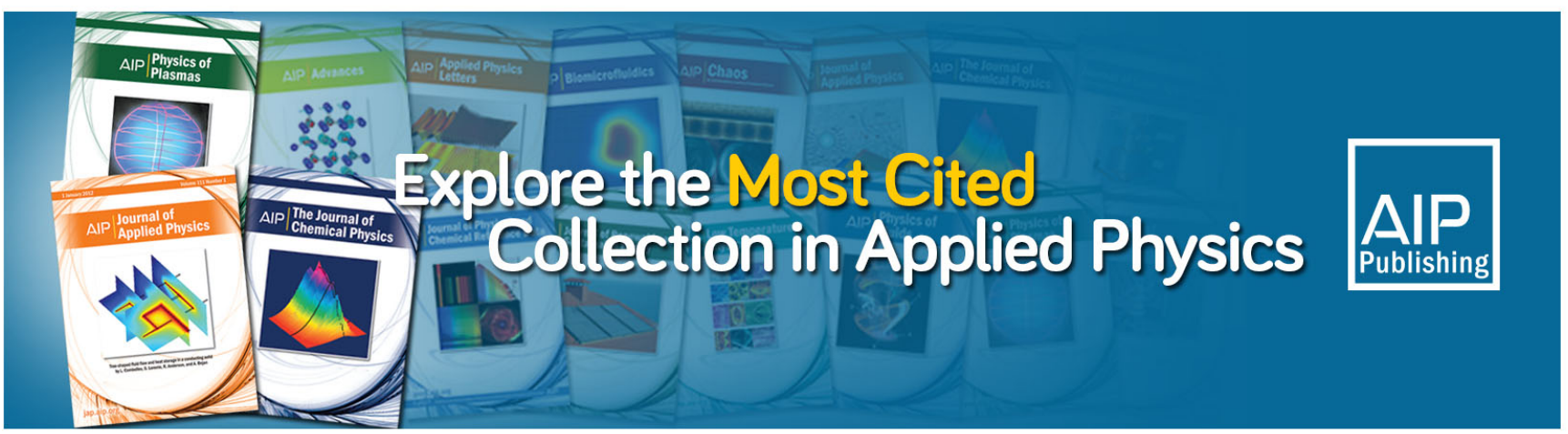




\title{
Fully relativistic calculations on the potential energy surfaces of the lowest 23 states of molecular chlorine
}

\author{
Luiz Guilherme M. de Macedo ${ }^{\text {a) }}$ \\ Laboratório de Simulação Computacional, Departamento de Quimica, Universidade Estadual Paulista \\ (UNESP), Bauru, São Paulo 17033-360, Brazil \\ Wibe A. de Jong \\ William R. Wiley Environmental Molecular Laboratory, Pacific Northwest National Laboratory, \\ P.O. Box 999, Richland, Washington 99352, USA
}

(Received 13 November 2007; accepted 30 November 2007; published online 24 January 2008)

\begin{abstract}
The electronic structure and spectroscopic properties $\left(R_{e}, \omega_{e}, \omega_{e} x_{e}, \beta_{e}\right.$, and $\left.T_{e}\right)$ of the ground state and the 22 lowest excited states of chlorine molecule were studied within a four-component relativistic framework using the MOLFDIR program package. The potential energy curves of all possible 23 covalent states were calculated using relativistic complete open shell configuration interaction approach. In addition, four component multireference configuration interaction with single and double excitation calculations were performed in order to infer the effects due to dynamical correlation in vertical excitations. The calculated properties are in good agreement with the available experimental data. (C) 2008 American Institute of Physics. [DOI: 10.1063/1.2827457]
\end{abstract}

Chlorine, one of the few homonuclear diatomic molecules, which exists under normal conditions in nature, is a commonly used industrial commodity. ${ }^{1}$ It is one of the top ten chemicals produced (by gross weight) and it has wide range of applications, as bleaching agent for paper, chlorinated solvents, for water purification, and other chemical processes including pharmaceuticals. In addition, it is of atmospheric and environmental interest, ${ }^{2}$ it is a plasma processing gas $^{3}$ used in plasma etching of semiconductors, and it has gas ultraviolet (UV) laser applications. ${ }^{4,5}$

Despite its economical and technological importance, several features in its spectra remain unclear. It is known that the first absorption band of $\mathrm{Cl}_{2}$ molecule is located in the UV region with a maximum at $330 \mathrm{~nm}$ and corresponds to the $\mathrm{Cl}_{2}$ excitation to the valence states correlating with the $\mathrm{Cl}\left({ }^{2} P_{3 / 2}\right)$ and $\mathrm{Cl}\left({ }^{2} P_{1 / 2}\right)$ atomic asymptotes, identified in this paper as $\mathrm{Cl}$ and $\mathrm{Cl}^{*}$, respectively.

The absorption spectrum is attributed mostly to the transition from the ground state $X^{1} \Sigma_{g}^{+}$to the lowest repulsive $C^{1} \Pi\left(1_{u}\right)$ state. In the red wing, $A^{3} \Pi(1 u) \leftarrow X$ and $B^{3} \Pi\left(0_{u}^{+}\right) \leftarrow X$ continuum bands are visible, though they are much weaker than the main $C \leftarrow X$ peak. ${ }^{6}$ In the adiabatic case, $^{7}$ the $A$ and $C$ states correlate to the ground state asymptote, $\mathrm{Cl}+\mathrm{Cl}$, while the $B$ state correlates to a higher dissociation limit, $\mathrm{Cl}+\mathrm{Cl}^{*}$. So far, much effort has been made on surveying the dissociation behavior ${ }^{8-12}$ of $\mathrm{Cl}_{2}$. Experimental information on the $B \leftarrow X$ absorption band is quite uncertain, since it is significantly overlapped by the the more intense $C \leftarrow X$ band as well as the weaker $A \leftarrow X$ band. The uncertainty about the $B \leftarrow X$ absorption band is so significant that

\footnotetext{
a) Author to whom correspondence should be addressed. Electronic mail: $\lg @$ fc.unesp.br.
}

the vertical excitation energy of the $B$ state differs by thousands of wave numbers in different studies. ${ }^{9,13,14}$ The $A$ state is even more difficult to obtain because the $A \leftarrow X$ transition is very weak. As a consequence, information about the potential energy curves for relevant excited states is far from being complete and ambigious. Only the lowest five states $\left[X^{1} \Sigma_{g}^{+}, B^{3} \Pi\left(0_{u}^{+}\right), A^{\prime}{ }^{3} \Pi\left(2_{u}\right), A^{3} \Pi\left(1_{u}\right)\right.$, and $\left.B^{\prime}{ }^{3} \Pi\left(0_{u}^{-}\right)\right]$of the 23 possible valence states ${ }^{15}$ are well characterized experimentally, $^{16-19}$ in spite of many experimental efforts. $^{20-25}$

The first $a b$ initio potential curves for the $\mathrm{Cl}_{2}$ molecule were computed by Peyerimhoff and Buenker ${ }^{26}$ more than 25 years ago under the $\Lambda-\Sigma$ approximation and served as the mainly theoretical basis for analysis of experimental data. Although semiempirical relativistic intermediate neglect of differential overlap (INDO) calculations were performed in $\mathrm{Cl}_{2} 15$ years ago, ${ }^{27}$ only recently, ab initio calculations including spin-orbit coupling have been performed ${ }^{28-33}$ for some low lying valence states (usually) applying a relativistic core potential approach. Therefore, high accurate theoretical potential curves are of interest to understand $\mathrm{Cl}_{2}$ spectra, as well as the analysis of nonadiabatic processes ${ }^{34}$ and experimental data regarding the $\mathrm{Cl}_{2}$ dissociation.

The goal in the present work is to obtain a detailed theoretical description of the spectroscopic properties for all 23 valence states of $\mathrm{Cl}_{2}$ dissociating into neutral atoms. For this purpose, correlated four-component relativistic calculations were carried out to determine the potential energy curves of all states that correlate into the ${ }^{2} P_{J}+{ }^{2} P_{J}(J=3 / 2$ or $1 / 2)$ states using the average of configurations Dirac-HartreeFock approach. ${ }^{35}$ This approach allows us to assess the spinorbit coupling on the spectroscopic properties and makes it possible to assign all 23 covalent states. In order to obtain better relativistic vertical excitation energies, supplementary multireference configuration interaction with single and 
TABLE I. Spectroscopic properties for the excited states of chlorine (improved potential energy curves based on COSCI results).

\begin{tabular}{|c|c|c|c|c|c|c|c|c|}
\hline State & & $R_{e}(\AA)$ & $D_{e}(\mathrm{eV})$ & $D_{0}(\mathrm{eV})$ & $\omega_{e}\left(\mathrm{~cm}^{-1}\right)$ & $\omega_{e} x_{e}\left(\mathrm{~cm}^{-1}\right)$ & $B_{e}\left(\mathrm{~cm}^{-1}\right)$ & $T_{e}(\mathrm{eV})$ \\
\hline \multirow[t]{6}{*}{$X:(1)_{g}^{+}$} & This work & 1.987 & 2.51 & \multirow[t]{6}{*}{2.48} & 563 & 2.86 & 0.244 & \multirow[t]{6}{*}{0.00} \\
\hline & Expt. & $1.988^{\mathrm{a}}$ & $2.49^{\mathrm{a}}$ & & $559.75^{\mathrm{a}}$ & & $0.244^{\mathrm{b}}$ & \\
\hline & Expt. & & $2.51^{\mathrm{c}}$ & & $559.72^{\mathrm{d}}$ & $2.72^{\mathrm{d}}$ & & \\
\hline & Expt. & & & & $559.71^{\mathrm{e}}$ & $2.70^{\mathrm{e}}$ & $0.243^{\mathrm{e}}$ & \\
\hline & Theor. ${ }^{\mathrm{f}}$ & $2.017^{\mathrm{f}}$ & $2.33^{\mathrm{f}}$ & & $549.7^{\mathrm{f}}$ & $2.78^{\mathrm{f}}$ & & \\
\hline & Theor. $^{\mathrm{g}}$ & $2.013^{\mathrm{g}}$ & $2.40^{\mathrm{g}}$ & & $549^{\mathrm{g}}$ & $2.98^{\mathrm{g}}$ & & \\
\hline \multirow[t]{2}{*}{$A^{\prime}:(1) 2_{u}$} & This work & 2.473 & 0.39 & \multirow[t]{2}{*}{0.38} & 244 & 4.21 & 0.158 & 2.12 \\
\hline & Expt. & $2.431^{\mathrm{h}}$ & $0.39^{\mathrm{h}}$ & & $258^{\mathrm{h}}$ & $5.46^{\mathrm{h}}$ & $0.163^{\mathrm{h}}$ & $2.13^{\mathrm{b}, \mathrm{h}}$ \\
\hline \multirow[t]{5}{*}{$A:(1) 1_{u}$} & This work & 2.478 & 0.36 & \multirow[t]{5}{*}{0.34} & 241 & 4.35 & \multirow[t]{5}{*}{0.157} & 2.16 \\
\hline & Expt. & $2.433^{\mathrm{i}}$ & $0.31^{\mathrm{f}}$ & & $265^{\mathrm{i}}$ & $5.14^{\mathrm{i}}$ & & $2.16^{\mathrm{b}}$ \\
\hline & Expt. & $2.43^{j}$ & $0.35^{\mathrm{j}}$ & & $256^{\mathrm{j}}$ & $5.1^{\mathrm{j}}$ & & $2.16^{\mathrm{j}}$ \\
\hline & Theor. ${ }^{f}$ & $2.467^{\mathrm{f}}$ & $0.29^{f}$ & & $237.5^{\mathrm{f}}$ & $5.76^{\mathrm{f}}$ & & \\
\hline & Theor $^{\mathrm{g}}$ & $2.450^{\mathrm{g}}$ & $0.29^{\mathrm{g}}$ & & $265^{\mathrm{g}}$ & $5.86^{\mathrm{g}}$ & & \\
\hline \multirow[t]{2}{*}{$B^{\prime}:(1) 0_{u}^{-}$} & This work & 2.480 & 0.32 & \multirow[t]{2}{*}{0.30} & 238 & 4.55 & 0.157 & 2.20 \\
\hline & Expt. $^{\mathrm{k}}$ & $2.430^{\mathrm{k}}$ & $0.31^{\mathrm{k}}$ & & $253^{\mathrm{k}}$ & $5.76^{\mathrm{k}}$ & $0.163^{\mathrm{k}}$ & $2.20^{\mathrm{k}}$ \\
\hline \multirow[t]{4}{*}{$B:(1) 0_{u}^{+}$} & This work & 2.475 & 0.42 & \multirow[t]{4}{*}{0.41} & 243 & 4.14 & 0.157 & 2.20 \\
\hline & Expt. & $2.435^{\mathrm{d}}$ & $0.42^{\mathrm{d}}$ & & $255.38^{\mathrm{d}}$ & 4.59 & \multirow[t]{3}{*}{$0.162^{b}$} & \multirow[t]{3}{*}{$2.21^{\mathrm{b}}$} \\
\hline & Theor. ${ }^{\mathrm{f}}$ & $2.464^{\mathrm{f}}$ & $0.36^{\mathrm{f}}$ & & $240^{\mathrm{f}}$ & $5.26^{\mathrm{f}}$ & & \\
\hline & Theor. $^{\mathrm{g}}$ & $2.450^{\mathrm{g}}$ & $0.40^{\mathrm{g}}$ & & $259^{\mathrm{g}}$ & $4.60^{\mathrm{g}}$ & & \\
\hline \multirow[t]{2}{*}{$B^{\prime \prime}:(2) 1_{u}$} & This work & 2.881 & 0.03 & 0.03 & 84 & 9.06 & 0.116 & 2.48 \\
\hline & Theor. & & & & & & & $2.45^{1}$ \\
\hline \multirow{6}{*}{$\begin{array}{l}(1) 2_{g} \\
a:(1) 1_{g} \\
a^{\prime}:(2) 0_{g}^{+} \\
(1) 0_{g}^{-} \\
(2) 1_{g}{ }^{\mathrm{g}} \\
(2) 0_{u}^{-}\end{array}$} & This work & 3.646 & 0.02 & 0.02 & 31 & -0.17 & 0.073 & 2.50 \\
\hline & This work & 3.477 & 0.03 & 0.03 & 42 & 2.23 & 0.080 & 2.49 \\
\hline & This work & 3.932 & 0.01 & 0.01 & 48 & 7.20 & 0.062 & 2.51 \\
\hline & This work & 3.337 & 0.03 & 0.03 & 47 & 5.67 & 0.087 & 2.60 \\
\hline & This work & 3.345 & 0.04 & 0.04 & 55 & 4.16 & 0.064 & 2.59 \\
\hline & This work & 3.932 & 0.00 & 0.00 & 36 & 14.12 & 0.062 & 2.51 \\
\hline \multirow[t]{2}{*}{ (3) $1_{u}$} & This work & 3.874 & 0.01 & 0.00 & 52 & 10.14 & 0.064 & 2.51 \\
\hline & Theor. & & & & & & & $2.56^{1}$ \\
\hline (3) $0_{g}^{+}$ & This work & 3.332 & 0.03 & 0.02 & 98 & 5.65 & 0.087 & 2.60 \\
\hline (3) $1_{g}^{\circ}$ & This work & 3.816 & 0.02 & 0.01 & 49 & 3.08 & 0.066 & 2.61 \\
\hline (2) $2_{g}$ & This work & 3.941 & 0.01 & 0.01 & 33 & 4.44 & 0.062 & 2.62 \\
\hline (4) $0_{g}^{+}$ & This work & 3.740 & 0.02 & 0.02 & 44 & 2.39 & 0.069 & 2.72 \\
\hline (3) $0_{u}^{-}$ & This work & 3.808 & 0.04 & 0.03 & 126 & 4.53 & 0.066 & 2.59 \\
\hline (1) $3_{u}$ & This work & 5.042 & 0.01 & 0.01 & 37 & 10.25 & 0.038 & 2.61 \\
\hline$b^{\prime}:(2) 2_{u}$ & This work & 3.891 & 0.02 & 0.01 & 37 & 2.84 & 0.064 & 2.61 \\
\hline (4) $1_{u}$ & This work & 4.738 & 0.00 & 0.00 & 16 & 7.14 & 0.043 & 2.63 \\
\hline$C:(5) 1_{u}$ & This work & 3.746 & 0.02 & 0.01 & 35 & 4.52 & 0.069 & 2.72 \\
\hline (4) $0_{u}^{-}$ & This work & 3.830 & 0.01 & 0.01 & 34 & 2.34 & 0.066 & 2.72 \\
\hline
\end{tabular}

${ }^{\mathrm{a}}$ Reference 43 .

${ }^{\mathrm{b}}$ Reference 45.

${ }^{\mathrm{c}}$ Reference 44.

${ }^{\mathrm{d}}$ References 31 and 16.

${ }^{\mathrm{e}}$ Reference 23.

${ }^{\mathrm{f}}$ Reference 28.

double excitation (MRCISD) calculations were also performed.

All calculations presented in this work were performed using the fully relativistic ab initio MOLFDIR (Ref. 36) program package in a similar way previously described in a paper from de Jong et al. ${ }^{37}$ The chlorine nucleus was represented by a Gaussian charge distribution ${ }^{38}$ with an exponential value of $0.3848274922 \times 10^{+09}$, and the basis set used
${ }^{\mathrm{g}}$ Reference 31.
${ }^{\mathrm{h}}$ Reference 17.
${ }^{\mathrm{i}}$ Reference 18.
${ }^{\mathrm{j}}$ Reference 24.
${ }^{\mathrm{k}}$ Reference 19.
${ }^{\mathrm{l}}$ Reference 46.

was the contracted aug-cc-pVTZ basis taken from Visscher and Dyall. ${ }^{39}$ The speed of light was taken to be 137.0359895 a.u.

The potential energy surfaces of all the states were calculated at 46 different bond distances using the average of configurations Dirac-Hartree-Fock followed by the complete open shell configuration interaction (COSCI) approach, where full $\mathrm{Cl}$ was performed in the open shell space of the 
TABLE II. Calculated relativistic vertical excitation energies $(\mathrm{eV})$ at the experimental ground state equilibrium length compared to literature data.

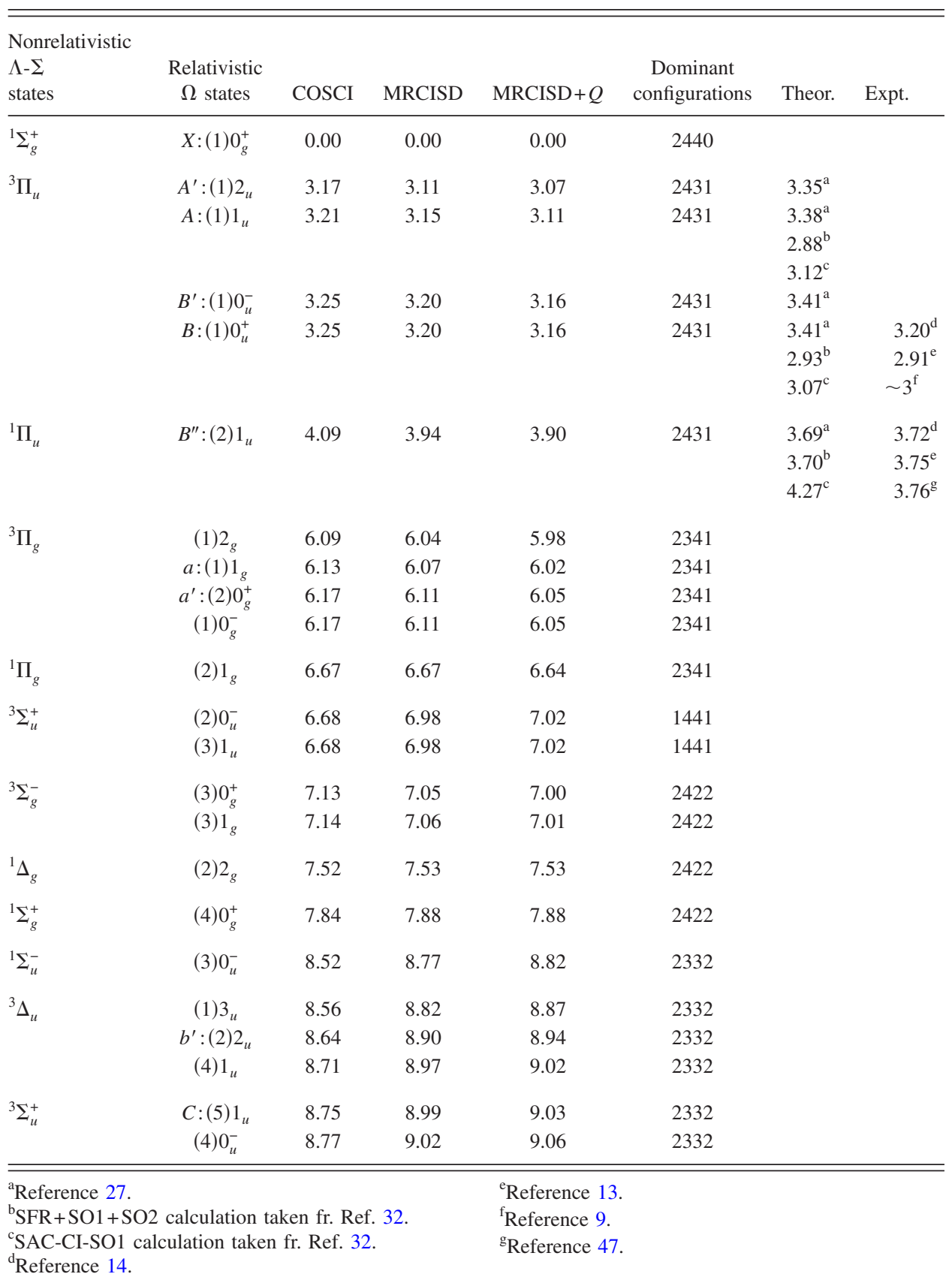

$3 p$ spin orbitals. Since performing a multireference $\mathrm{Cl}$ at all points of the potential energy surface would be computationally very expensive, we pragmatically improved the curves by a simple empirical correction, ${ }^{40,37}$ matching the ground state potential energy curve to the experimentally determined Rydberg-Klein-Rees ground state ${ }^{20}$ and shifting all the excited states in a similar fashion.

MRCISD calculations were performed to estimate the effects of dynamical correlation and relaxation on the vertical excitation energies and they were calculated at the experimental ground state $R_{e}$. Higher order corrections were estimated using the so-called Davidson correction, ${ }^{41}$ denoted as $\mathrm{MRCISD}+Q$. The multireference active space contains the $3 s$ spinor in RAS1, the $3 p$ spinors in RAS2, and 160 virtual spinors in RAS3, and the COSCI wave functions were used as the reference wave functions for these calculations. The RAS3 space encompasses all virtuals with energies of less than 4.26 hartrees in COSCI calculation.

The equilibrium bond lengths $\left(R_{e}\right)$, vibrational frequencies $\left(\omega_{e}\right)$, anharmonicity contants $\left(\omega_{e} x_{e}\right)$, rotational contant $\left(\beta_{e}\right)$, and dissociation energies $\left(D_{e}\right)$ were obtained through 15th-order polynomial fit using FIT_1D (Ref. 42) program.

Potential energy curves of the 22 lowest excited states and ground state that dissociate into neutral atoms $(\mathrm{Cl}+\mathrm{Cl}$, $\mathrm{Cl}+\mathrm{Cl}^{*}$, and $\mathrm{Cl}^{*}+\mathrm{Cl}^{*}$ ), resulting from $\sigma_{g}^{k} \pi_{u}^{l} \pi_{g}^{m} \sigma_{u}^{n}$ configurations where $k+l+m+n=10$ electrons in 12 spin orbitals, were calculated. The calculated spectroscopic parameters $\left(R_{e}, \omega_{e}, \omega_{e} x_{e}, D_{e}, D_{0}, \beta_{e}\right.$, and $\left.T_{e}\right)$ for these states are presented in Table I together with available experimental 
data $^{43-45}$ and results from other theoretical work. ${ }^{46}$

Comparing our results with the experimental values available, we found that (a) the calculated bond distances $\left(R_{e}\right)$ for the excited states are all systematically larger by less than $0.05 \AA$, (b) the values of $D_{e}$ have discrepancies smaller than $0.01 \mathrm{eV}$ for the majority of states, (c) the vibrational frequencies $\omega_{e}$ are within $15 \mathrm{~cm}^{-1}$, and (d) the differences for $\beta_{e}$ are less than $6 \mathrm{~cm}^{-1}$ and $T_{e}$ values are $0.01 \mathrm{eV}$ lower for the worse cases.

For the 18 higher covalent states, there are only theoretical $T_{e}$ values for two states: (2) $1_{u}$ and (3) $1_{u}$, with values of 2.45 and $2.56 \mathrm{eV}$, respectively. Our COSCI values for these states are 2.48 and $2.51 \mathrm{eV}$, respectively. For all other states, the spectroscopic constants are presented for the first time. Generally, the splitting of the calculated states due to spinorbit interaction agrees reasonably well with the observed splittings and the nondynamical correlation effects are apparently sufficiently described by COSCI calculations in the spinor space spanned by the $3 p$ spinors.

In Table II, the calculated vertical excitation energies are presented. The results are compared with those of Peyerimhoff and Buenker, ${ }^{26}$ Roszak and Lipinski, ${ }^{27}$ and available experimental data. ${ }^{9,13,14,47}$ The assignment is given to the states based on their main character at the ground state $R_{e}$.

Experimental values of vertical excitations are available for two states, $B:(1) 0_{u}^{+}$and (2) $1_{u}$. The experimental values of vertical excitation for $B:(1) 0_{u}^{+}$vary from 2.90 to $3.20 \mathrm{eV}$ (Samartzis et al. ${ }^{9}$ suggest a value close to $3 \mathrm{eV}$ ), whereas the experimental values for (2) $1_{u}$ state are closer to each other, 3.72 and $3.75 \mathrm{eV}$. Our theoretical results are in reasonable agreement with available experimental data, being at relativistic MRCISD $+Q$ level, 3.26 and $3.90 \mathrm{eV}$ for $B:(1) 0_{u}^{+}$and (2) $1_{u}$, respectively. From Table II, it can be seen that the dynamical correlation is important to obtain accurate vertical excitation energies. For the state $(2) 1_{u}$, the excitation energy lowers from the COSCI value of 4.09 to $3.94 \mathrm{eV}$ at MRCISD level and $3.90 \mathrm{eV}$ at MRCISD $+Q$ level.

There are just few theoretical calculations with spinorbit coupling and experimental work regarding the vertical excitation energies of $\mathrm{Cl}_{2}$, and they are concentrated on relativistic states that originated from nonrelativistic ${ }^{3} \Pi_{u}\left[A^{\prime}:(1) 2_{u}, A:(1) 1_{u}, B^{\prime}: 0_{u}^{-}\right.$, and $\left.B: 0_{u}^{+}\right]$and ${ }^{1} \Pi_{u}\left[(2) 1_{u}\right]$

Roszak and Lipinski, ${ }^{27}$ using a semiempirical INDO with spin-orbit corrections, found very good agreement for vertical excitation energy of (2) $1_{u}$ state but a worse agreement for $B: 0_{u}^{+}$. Honda et al., ${ }^{32}$ using a spin-free (scalar relativistic) Hamiltonian with one- and two-electron spin-orbit interactions (SFR $+\mathrm{SO} 1+\mathrm{SO} 2)$ and symmetry adapted cluster $\mathrm{Cl}$ with one-electron spin-orbit interactions (SAC-CISO1), studied three excited states of chlorine molecule $\left[A:(1) 1_{u}, B: 0_{u}^{+}\right.$, and (2) $\left.1_{u}\right]$. They found for (2) $1_{u}$ state values of $3.70 \mathrm{eV}$ (SAC-CI-SO1) and $4.27 \mathrm{eV}(\mathrm{SFR}+\mathrm{SO} 1+\mathrm{SO} 2)$, while as described before, we found a $3.90 \mathrm{eV}$ value at MRCISD $+Q$ level.

With respect to $B: 0_{u}^{+}$, Honda et al. ${ }^{32}$ found the values of $2.93 \mathrm{eV}$ (SAC-CI-SO1) and $3.07 \mathrm{eV}$ (SFR+SO1+SO2), which are between the lowest $(2.91 \mathrm{eV})$ and highest $(3.20 \mathrm{eV})$ experimental values available. Our relativistic MRCISD $+Q$ for $B: 0_{u}^{+}$and $B^{\prime}: 0_{u}^{-}$are both $3.16 \mathrm{eV}$. Roszak and Lipinski found also found an equal value for $B: 0_{u}^{+}$and $B^{\prime}: 0_{u}^{-}$, but it is $3.42 \mathrm{eV}$.

For the $A:(1) 1_{u}$ state, there are only theoretical values. Our MRCISD $+Q$ value, $3.11 \mathrm{eV}$, is very similar to the value found by Honda et al. $^{32}$ with SAC-CI-SO1 approach, $3.12 \mathrm{eV}$. The $\mathrm{SFR}+\mathrm{SO} 1+\mathrm{SO} 2$ result by Honda et $a .^{32}$ is found to be significantly lower $(2.88 \mathrm{eV})$, whereas the value found by Roszak and Lipinski for this state is considerably higher $(3.38 \mathrm{eV})$ compared with our MRCISD $+Q$ result.

The spectroscopic properties and potential energy curves of the ground state and all possible covalent excited states for $\mathrm{Cl}_{2}$ molecule were calculated within a four-component relativistic framework with COSCI approach. Tables I and II display the spectroscopic properties derived from their curves and the results are in good agreement with available data. The corrected curves for all states with their assignment can be downloaded as Supplementary Material. ${ }^{48}$

This research was performed in part using the Molecular Science Computing Facility (MSCF) in the William R. Wiley Environmental Molecular Sciences Laboratory (EMSL), a national scientific user facility sponsored by the U.S. Department of Energy's Office of Biological and Environmental Research and located at the Pacific Northwest National Laboratory (PNNL), operated for the Department of Energy by Battelle. L.G.M. de Macedo also would like to acknowledge Fundação de Amparo à Pesquisa do Estado de São Paulo (FAPESP) for Junior Scientist Fellowship (Grant Nos. 07/50679-9 and 06/64976-5).

${ }^{1}$ R. B. Evans, Lung 183, 151 (2004).

${ }^{2}$ D. Maric, J. P. Burrows, R. Miller, and G. K. Moortget, J. Photochem. Photobiol., A 70, 205 (1993).

${ }^{3}$ M. V. Malyshev, V. M. Donnely, and S. Samukawa, J. Appl. Phys. 84, 1222 (1998).

${ }^{4}$ D. R. Bates, Adv. At. Mol. Phys. 20, 1 (1985).

${ }^{5}$ W. L. Morgan, Plasma Chem. Plasma Process. 12, 449 (1992).

${ }^{6}$ G. Herzberg, Molecular Spectra and Molecular Structure Spectra of Diatomic Molecules (Van Nostrand Reinhold, New York, 1950).

${ }^{7}$ G. E. Busch, R. T. Mahoney, R. I. Morse, and K. R. Wilson, J. Chem. Phys. 51, 449 (1969).

${ }^{8}$ A. J. Alexander, Z. H. Kim, S. A. Kandel, R. N. Zare, T. P. Rakitis, Y. Asano, and S. Yabushita, J. Chem. Phys. 113, 9022 (2000).

${ }^{9}$ P. C. Samartzis, B. L. G. Bakker, T. P. Rakitzis, D. H. Parker, and T. N. Kitsopoulos, J. Chem. Phys. 110, 5201 (1999).

${ }^{10}$ M. J. Bass, M. Brouard, A. P. Clark, C. Vallence, and B. Martinez-Haya, Phys. Chem. Chem. Phys. 5, 856 (2003).

${ }^{11}$ Y. Matsumi, K. Tonokura, and M. Kawasaki, J. Chem. Phys. 97, 1065 (1992).

${ }^{12}$ Y. Matsumi, M. Kawasaki, T. Sato, and T. Arikawa, Chem. Phys. Lett. 155, 486 (1989).

${ }^{13}$ R. S. Mulliken, Phys. Rev. 57, 500 (1940).

${ }^{14}$ J. A. Coxon, Molecular Spectroscopy (Chemical Society, London, 1973), Vol. 1.

${ }^{15}$ L. Li, R. J. Lipert, J. Lobue, W. A. Chupka, and S. D. Colson, Chem. Phys. Lett. 151, 335 (1988).

${ }^{16}$ J. A. Coxon, J. Mol. Spectrosc. 82, 264 (1980).

${ }^{17}$ P. Tellinghuisen, B. Guo, D. K. Chakraborty, and J. Tellinghuisen, J. Mol. Spectrosc. 128, 268 (1988).

${ }^{18}$ T. Ishiwata, A. Ishiguro, and K. Obi, J. Mol. Spectrosc. 147, 300 (1991).

${ }^{19}$ T. Ishiwata, Y. Kasai, and K. Obi, J. Chem. Phys. 95, 60 (1991).

${ }^{20}$ A. E. Douglas and A. R. Hoy, Can. J. Phys. 53, 1965 (1975).

${ }^{21}$ V. E. Bondybey and C. Fletcher, J. Chem. Phys. 64, 3615 (1976).

${ }^{22}$ J. A. Coxon and R. Shanker, J. Mol. Spectrosc. 69, 109 (1978).

${ }^{23}$ D. Bermejo, J. J. Jimenez, and R. Z. Martinez, J. Mol. Spectrosc. 212, 86 (2002).

${ }^{24}$ J. Tellinghuisen and D. K. Chakraborty, Chem. Phys. Lett. 134, 565 
(1987).

${ }^{25}$ T. Moeller, B. Jordan, P. Gürtler, G. Zimmerer, D. Haaks, J. Le Calve, and M. C. Castex, Chem. Phys. 76, 295 (1983).

${ }^{26}$ S. D. Peyerimhoff and R. J. Buenker, Chem. Phys. 57, 279 (1981).

${ }^{27}$ S. Roszak and J. Lipinski, Int. J. Quantum Chem. 44, 831 (1992).

${ }^{28}$ Y. Asano and S. Yabushita, J. Phys. Chem. A 105, 9873 (2001).

${ }^{29}$ Y. Asano and S. Yabushita, Chem. Phys. Lett. 372, 348 (2003).

${ }^{30}$ Y. Asano and S. Yabushita, Bull. Korean Chem. Soc. 24, 703 (2003).

${ }^{31}$ D. B. Kock, A. B. Alekseyev, and R. J. Buenker, J. Chem. Phys. 120, 11549 (2004).

${ }^{32}$ Y. Honda, M. Hada, M. Ehara, H. Nakatsuji, and J. Michl, J. Chem. Phys. 123, 164113 (2005)

${ }^{33}$ H. S. Lee, W. K. Cho, Y. J. Choi, and Y. S. Lee, Chem. Phys. 311, 121 (2005).

${ }^{34}$ A. P. Clark, M. Brouard, F. Quadrini, and C. Valence, Phys. Chem. Chem. Phys. 8, 5591 (2006).

${ }^{35}$ O. Visser, L. Visscher, P. J. C. Aerts, and W. C. Nieuwpoort, J. Chem Phys. 96, 2910 (1992).

${ }^{36}$ L. Visscher, O. Visser, P. J. C. Aerts, H. Merenga, and W. C. Nieuwpoort, Comput. Phys. Commun. 81, 120 (1994).

${ }^{37}$ W. A. de Jong, L. Visscher, and W. C. Nieuwpoort, J. Chem. Phys. 107,
9046 (1997)

${ }^{38}$ L. Visscher and K. G. Dyall, At. Data Nucl. Data Tables 67, 207 (1997).

${ }^{39}$ L. Visscher and K. G. Dyall, J. Chem. Phys. 104, 9040 (1995).

${ }^{40}$ J. Teichteil, J. Chem. Phys. 87, 963 (1990).

${ }^{41}$ S. R. Langhoff and E. R. Davidson, Int. J. Quantum Chem. 8, 61 (1974).

${ }^{42}$ K. A. Peterson, "FIT_1D code," Ph.D. thesis, University of WisconsinMadison, 1990.

${ }^{43}$ K. P. Huber and G. Herzberg, Constants of Diatomic Molecules (Van Nostrand Reinhold, New York, 1979).

${ }^{44}$ R. J. Leroy and R. B. Bernstein, J. Mol. Spectrosc. 37, 109 (1971).

${ }^{45}$ See http://webbook.nist.gov for a compilation of some spectroscopic constants of $\mathrm{Cl}_{2}$.

${ }^{46}$ D. Zhang, A. Abdel-Hafiez, and B. Zhang, Chem. Phys. Lett. 428, 49 (2006).

${ }^{47}$ M. Brith, M. D. Rowe, O. Schnepp, and P. J. Stephens, Chem. Phys. 9, 57 (1975)

${ }^{48}$ See EPAPS Document No. E-JCPSA6-128-025802 for the corrected curves for all 23 states. This document can be reached through a direct link in the online article's HTML reference section or via EPAPS homepage (http://www.aip.org/pubservs/epaps.html). 